\title{
Characterizing the Spatial Distribution of Coral Reefs in the South-Central Coast Region of Vietnam using Planetscope Imagery
}

\author{
Khanh V Nguyen ${ }^{1}$, Vinh C Duong ${ }^{2}$, Kinh T Kieu ${ }^{1}$, Thuong Tran ${ }^{\text {Corresp., }}{ }^{3}$, Cho-ying Huang ${ }^{4}$, Ruth Reef ${ }^{5}$, Thien M \\ Hoang ${ }^{1}$ \\ ${ }^{1}$ Faculty of Biology and Environment, University of Science and Education, The University of Danang, Danang, Danang, Vietnam \\ 2 Department of Environment and Natural Recourses, Gia Lai Campus, Nong Lam University - Ho Chi Minh, Buon Me Thuot, Gia Lai, Vietnam \\ 3 Institute of Engineering and Technology, Thu Dau Mot University, Thu Dau Mot city, Binh Duong province, Vietnam \\ 4 Department of Geography, National Taiwan University, Taipei, Taiwan \\ 5 School of Earth, Atmosphere and Environment, Monash University, Clayton, Victoria, Australia \\ Corresponding Author: Thuong Tran \\ Email address: thuong.tran@tdmu.edu.vn
}

This study aims to understand the spatial distribution of coral reefs in the central region of Vietnam. We classified live coral cover in Son Tra Peninsula (ST) and Cu Lao Cham Island $(C L C)$ in the South-Central Coast Region of Vietnam using the Maximum Likelihood Classifier on $3 \mathrm{~m}$ Planetscope imagery. Confusion matrices and the accuracy of the classifier were assessed using field data (1,543 and 1,560 photographs in ST and CLC, respectively). The results showed that the reef's width ranged from 30 to $300 \mathrm{~m}$ across the study site, and we were able to detect live coral cover across a depth gradient of 2 to $6 \mathrm{~m}$ below the sea surface. The overall accuracies of the classifier (the Kappa coefficient) were $76.78 \%(0.76)$ and $78.08 \%(0.78)$ for ST and CLC, respectively. We found that $60.25 \%$ of coral reefs in ST were unhealthy and the live coral cover was less than $50 \%$, while $25.75 \%$ and $11.46 \%$ of those in CLC were in good and excellent conditions, respectively. This study demonstrates the feasibility of utilizing Planetscope imagery to monitor shallow coral reefs of small islands at a high spatial resolution of $3 \mathrm{~m}$. The results of this study provide valuable information for coral reef protection and conservation. 
1 Characterizing the Spatial Distribution of Coral Reefs

2 in the South-Central Coast Region of Vietnam using

3 Planetscope Imagery

Khanh V. Nguyen ${ }^{1}$, Vinh C. Duong ${ }^{2}$, Kinh T. Kieu ${ }^{1}$, Thuong V. Tran ${ }^{3 *}$, Cho-ying Huang ${ }^{4}$, Ruth Reef $^{5}$, Thien M. Hoang ${ }^{1}$

7

${ }^{1}$ Faculty of Biology and Environment, University of Science and Education, The University of Danang, Danang city, Viet Nam.

${ }^{2}$ Department of Environment and Natural Recourses, Gia Lai Campus, Nong Lam University Ho Chi Minh, Gia Lai province, Viet Nam.

${ }^{3}$ Institute of Engineering and Technology, Thu Dau Mot University, Binh Duong province, Viet Nam.

${ }^{4}$ Department of Geography, National Taiwan University, Taipei, Taiwan.

${ }^{5}$ School of Earth, Atmosphere and Environment, Monash University, Clayton, Victoria, Australia

Corresponding Author: Thuong V. Tran*

No. 6, Nguyen Van On street, Thu Dau Mot city, Binh Duong province, 75000, Viet Nam. Email address: thuong.tran@tdmu.edu.vn

\section{Abstract}

This study aims to understand the spatial distribution of coral reefs in the central region of Viet Nam. We classified live coral cover in Son Tra Peninsula (ST) and Cu Lao Cham Island (CLC) in the South-Central Coast Region of Viet Nam using the Maximum Likelihood Classifier on $3 \mathrm{~m}$ Planetscope imagery. Confusion matrices and the accuracy of the classifier were assessed using field data (1,543 and 1,560 photographs in ST and CLC, respectively). The results showed that the reef's width ranged from 30 to $300 \mathrm{~m}$ across the study site, and we were able to detect live coral cover across a depth gradient of 2 to $6 \mathrm{~m}$ below the sea surface. The overall accuracies of the classifier (the Kappa coefficient) were $76.78 \%(0.76)$ and $78.08 \%(0.78)$ for ST and CLC, respectively. We found that $60.25 \%$ of coral reefs in ST were unhealthy and the live coral cover was less than $50 \%$, while $25.75 \%$ and $11.46 \%$ of those in CLC were in good and excellent conditions, respectively. This study demonstrates the feasibility of utilizing Planetscope imagery to monitor shallow coral reefs of small islands at a high spatial resolution of $3 \mathrm{~m}$. The results of this study provide valuable information for coral reef protection and conservation. 


\section{Introduction}

39 Coral reefs make up only $0.1 \%$ of the global ocean substrate, yet they are one of the most 40 biodiverse marine ecosystems and they play a key role in providing a range of ecosystem services 41 (Hoegh-Guldberg, Pendleton \& Kaup, 2019; Obura et al., 2019; Pawlik \& McMurray, 2020).

42 Southeast Asia contains the largest area of coral reef cover on Earth, estimated at $91,700 \mathrm{~km}^{2}$, 43 followed by the Australia - Papua New Guinea region at 62,800 km² (Guan et al., 2020). Coral 44 cover in the SE Asia region has declined and is being threatened by both local and global stressors such as marine pollution and runoff, direct destruction, overexploitation of key species, outbreaks of coral predators, and climate change (Zhou et al., 2018; Hoegh-Guldberg, Pendleton \& Kaup, 2019; Carriger, Yee \& Fisher, 2021). Long term monitoring programs of coral health in the SE Asia region are important for managing this global biodiversity hotspot which is facing a range of impacts (Tun et al., 2008), Characterize coral reef cover and health over large spatial and temporal scales is critical for the effective management and protection of coral reef resources (McCarthy et al., 2017; Zhou et al., 2018). The use of remote sensing to monitor reefs over large temporal and spatial scales will be necessary to provide standardized data for reef health across the SE Asian region over this period of rapid change and population growth.

Coral reef monitoring applies both quantitative measurements to explore area coverage of basic reef bottom-types (e.g., coral cover), and provides information about coral reef health. These monitoring frameworks are designed to develop effective strategies for management, conservation, and restoration of coral reefs across various spatial scales (Guan et al., 2020; Carriger, Yee \& Fisher, 2021). Coral coverage and health is conducted using two primary approaches including insitu surveys and remotely sensed data (Hedley et al., 2016, 2018; McCarthy et al., 2017; GonzalezRivero et al., 2020). In-situ methods provide a high resolution images from a handle camera and compositionally detailed quantitative description of coral reef biodiversity, through SCUBA driver surveys (e.g., underwater geo-located digital photography) or high resolution aerial images that are costly and time consuming (Levy et al., 2018; Li et al., 2019). Thus, while in-situ methods can provide unrivaled detail on species diversity, coral density, and individual colony size and health; the spatiotemporal scale of these analyses is limited and biased against remote reefs, periods of severe weather conditions, or challenging reef topography (Levy et al., 2018). Satellite remote sensing to acquire coral information at different scales has been a cost-effective alternative or complement for in-situ surveys (Hedley et al., 2018; Levy et al., 2018; Zhou et al., 2018; Li et al., 2019). Among various sensors, the medium spatial resolution $(30 \mathrm{~m})$ Landsat images has been the most widely used for regional mapping coarse coral habitat classes (e.g., 04 classes) (Tobler, 1988; Zhou et al., 2018). Recently, freely available (for education and research programs) high spatial resolution $(3 \mathrm{~m})$ Planetscope imagery has demonstrated potential in coral pattern observation providing daily images (Lemajic, Vajsová \& Aastrand, 2018; Lazuardi, Wicaksono \& Marfai, 2021; Mansaray et al., 2021; Wulandari \& Wicaksono, 2021). 
77 Viet Nam has a large marine area with over 3,260 $\mathrm{km}$ of coastline and more than 3,000 islands 78 (Nguyen \& Nguyen, 2014). The distribution of coral reefs in Viet Nam is along the coast and 79 around offshore islands, and is categorized into five separate regions (i.e., western Tonkin Gulf, 80 Middle-central, South-central, South-eastern, and South-western) (Hedberg et al., 2017). The 81 highest coral diversity is in the South-Central area (SCA) with 400 coral species recorded (i.e., 82 Son Tra Peninsula [ST], Da Nang, Cu Lao Cham Island [CLC], Nha Trang, and Ninh Hai) 83 (Latypov \& Selin, 2008; Nguyen \& Vo, 2013). However, the health of coral reefs (as defined by 84 live coral cover) in the SCA has noticeably declined in the past few decades, with the condition of $85 \sim 50 \%$ of the reefs in this region currently classified as poor/very poor and only $11.6 \%$ and $2.9 \%$ 86 of the reefs classified as being in good and excellent conditions, respectively (Nguyen \& Phan, 87 2008; Nguyen, 2009; Nguyen \& Vo, 2013). Previous studies utilized various medium and high 88 spatial resolutions satellite data such as Landsat, SPOT-5, GeoEye-1, IKONOS, QuickBird, and 89 90 VNRedsat-1 to map general reef bottom-types, coral coverage, and reef building or expansion in this region (Tran, Phinn \& Roelfsema, 2012; Nguyen, Luong \& Ho, 2015; Nguyen, Bui \& Nguyen, 2019; Nguyen et al., 2019a). However, these studies have not examined the spatial distribution of reef health (live coral cover). Therefore, the objectives of this study were: (i) to utilize Planetscope imagery, a free satellite for education and research programs, for determining coral reef types at a high spatial resolution; (ii) to understand spatial distribution of coral reef categories (i.e., live coral cover and classification of benthic categories) in ST and CLC in the South-Central area of Viet Nam.

97

\section{Materials \& Methods}

\section{Study sites}

The study areas (i.e., ST [108 $13^{\prime} 58.1^{\prime \prime E}-16^{\circ} 08^{\prime} 54.4^{\prime \prime} \mathrm{N}$ and $\left.108^{\circ} 20^{\prime} 22.4^{\prime \prime E}-16^{\circ} 05^{\prime} 16.2^{\prime \prime} \mathrm{N}\right]$ and CLC [108 $24^{\prime} 42.8^{\prime \prime} \mathrm{E}-15^{\circ} 58^{\prime} 57.7^{\prime \prime} \mathrm{N}$ and $\left.108^{\circ} 33^{\prime} 04.2^{\prime \prime} \mathrm{E}-15^{\circ} 53^{\prime} 58.4^{\prime \prime} \mathrm{N}\right]$ ) are nature reserve areas located in the South-central coast region of Viet Nam (Nguyen, Huynh \& Zhang, 2015; Hoang et al., 2019) (Figure 1). CLC was recognized as a world biosphere reserve by UNESCO in 2009 (Nguyen, Huynh \& Zhang, 2015). The study sites are located within the tropical monsoon region with a distinct dry season (January-July) receiving $600 \mathrm{~mm}$ rainfall over these 6 months and a rainy season, where $80 \%$ of the annual rainfall $(2,000 \mathrm{~mm})$ falls between the month of August to December. The annual mean temperature at the study areas is about $26^{\circ} \mathrm{C}$ with little seasonal variation. The region is regularly disturbed by typhoons and river run-off in the wet season, which can lead to destruction of reefs.

Figure 1. Location of study area (a) Son Tra Peninsula (ST) and (b) Cu Lao Cham Island (CLC).

The reefs at study area are shallow fringing reefs, with a diversity of 226 and 227 coral species in ST and CLC, respectively (Kimura, Tun \& Chou, 2014, 2018). Deposited materials on the ocean 115 floor in this region is sand and rubble, which deposit between the inner and outer reef regions. 
117 tourism, and small-scale fisheries. However, these reefs are under threat from an accumulation of 118 stressors such as human disruption, typhoons, new outbreaks of crown of thorns starfish, excess 119 terrigenous sediment output due to land use change, pollution, overfishing, destructive fishing, and 120 the mining of reefs for limestone (Nguyen \& Vo, 2013; Quach, 2018). A lack of regular monitoring has impacted on effective coral reef management and protection (Le, 2020).

124

125

126

127

128

129

130

131

132

133

134

135

136

137

138

139

140

141

142

143

144

145

146

147

148

149

150

151

152

153

154

155

156

\section{Data collection and Processing}

The Planetscope images ( $3 \mathrm{~m}$ spatial resolution) used in this study were obtained from the Planet Education and Research Program server (https://www.planet.com/markets/education-andresearch/) (Table 1). The wavelengths of Planetscope imagery cover the blue $(455-515 \mathrm{~nm})$, green $(500-590 \mathrm{~nm})$, red $(590-670 \mathrm{~nm})$, and near-infrared $(780-860 \mathrm{~nm})$ spectral regions (Gabr, Ahmed \& Marmoush, 2020). These images were acquired on 28 June 2019 (ST) and 08 August 2019 (CLC) with $0 \%$ of cloud cover and coordinate system projection of WGS 84/ UTM zone 49N. The images, acquired by a Dove satellite with additional postprocessing applied, known as the PlanetScope Ortho Scene Product (level 3B), were ortho-rectified, atmospherically corrected, and scaled to surface reflectance (Lemajic, Vajsová \& Aastrand, 2018).

Table 1. Details of the acquired Planetscope imagery

We carried out field surveys during August and September 2019 to gather information about the depth and features of the ocean bottom. The bottom features were measured following the 25's method, proposed by (Roelfsema, Phinn \& Joyce, 2006), in a grid of $5 \mathrm{~m} \mathrm{x} 5 \mathrm{~m}$ using an underwater camera (GoPro HERO 8, USA). Based on this approach, five photographs including the four corners and one center positions of a $1 \mathrm{~m}$ x $1 \mathrm{~m}$ quadrat were taken. The underwater photographs were ortho-rectified to control the spatial uncertainty to $<3 \mathrm{~m}$ in order to match the resolution of the satellite data. The depth and the coordinates of each photograph were recorded using a Hondex PS-7FL (Honda Electronics Ltd., Toyohashi, Japan) and Garmin GPS MAP 62sc (Garmin Ltd., Lenexa, Kansas, USA), respectively. In addition to photo capture in the $5 \times 5 \mathrm{~m}$ grid, underwater 360 video transects (CND713, CND Co., Ltd., Korea) were taken to determine the ocean floor classes (Table 2) in deep and homogenous areas before collecting substrate types (i.e., sand, and hard bottom) to reduce the cost of field survey. A total of 1,543 photographs and 167 video transects at ST and 1,560 photographs and 174 video transects at CLC were collected during the field campaign. The photos were filtered to select for good quality photographs demonstrating their ability to clearly identify the bottom feature. Five photographs were overlapped to create a transect and each transect was geo-referenced based on captured coordinates before analyzing the benthic composition by the Coral Point Count Excel (CPCe) software (Kohler \& Gill, 2006; Roelfsema, Phinn \& Joyce, 2006).

Bottom types, derived from the photographs of $1 \times 1 \mathrm{~m}$ quadrats, were identified into four classes (i.e., live coral [hard and soft coral], sand, hard bottom [rock, rubble, dead coral], deep water [> 
$15714 \mathrm{~m}]$ ) (Hill \& Wilkinson, 2004), and were used to calculate proportion of substrate composition. 158 The coral reef health in $5 \times 5 \mathrm{~m}$ grids was categorized as the 'poor', 'fair', 'good' or 'excellent' 159 condition based on live coral cover (Chou et al., 1995; Hill \& Wilkinson, 2004) (Table 2). Finally, 160 a part of the ground-truth samples was randomly selected for image classification training (see the 161 sub-section in Supervised classification and coral cover mapping). A total of 323 and 369

162

163

164

165

166

167

168

169

170

171

172

173

174

175

176

177

178

179

180

181

182

183

184

185

186

187

188

189

190

191

192

193

194

randomly selected ground-truth samples in the ST and CLC, respectively, were identified to assess classification accuracy. It included each classed category as follow: 1LC (69), 2LC (64), 3LC (47), HB (43), S (51), and D (49) in Son Tra and 1LC (62), 2LC (56), 3LC (54), 4LC (55), HB (43), S (55), and D (44) in Cu Lao Cham. (Table 2 and the Data Supplemental Files).

Table 2. Identification scheme of bottom types and coral reef health

\section{Sun glint correction and water column correction}

Sun glint occurs in images under conditions of clear skies, shallow waters (when wind generated waves disturb the surface), more so when images are acquired at a high spatial resolution (Hedley, Harborne \& Mumby, 2005). This phenomenon could be defined as the specular reflection of light from the water surface, when the component of sensor-received radiance due to the surface reflection is greater than the water-leaving radiance from sub-surface features (Kay, Hedley \& Lavender, 2009). Previous studies proposed sun-glint removal methods for ocean color applications with resolutions on the scale of 100-1,000 m (Wang \& Bailey, 2001; Hedley, Harborne \& Mumby, 2005; Kay, Hedley \& Lavender, 2009). However, these models could only correct moderate glint and large errors remain in the brightest glint areas (Kay, Hedley \& Lavender, 2009). Hence, a separate set of revised methods were developed for benthic remotely sensed data at high spatial resolutions $(<10 \mathrm{~m}$ ) (Hochberg, Andréfouët \& Tyler, 2003; Kay, Hedley $\&$ Lavender, 2009). These approaches use data from the near-infrared (NIR) to determine the amount of glint in the received signal (Hedley, Harborne \& Mumby, 2005; Kay, Hedley \& Lavender, 2009), thus improving data retrieval for bathymetry or coral habitat classification (Hochberg, Andréfouët \& Tyler, 2003; Hedley, Harborne \& Mumby, 2005; Kay, Hedley \& Lavender, 2009). In this study, the sun light correction of the Planetscope images were undertaken using a revised 'de-glinting' method (Hochberg, Andréfouët \& Tyler, 2003; Hedley, Harborne \& Mumby, 2005). Following this approach, the relationships between NIR and visible bands were explored by linear regression based on a sample of the image pixels. The pixel sample was collected from one or more region of the image where a range of sun glint is evident, but where the underlying spectral brightness would be expected to be consistent (normally deep-water areas) (Hedley, Harborne \& Mumby, 2005). If the slope of the regression line for band $i$ is $b_{i}$, then all pixels in the image could be de-glinted in band i, following Equation (1):

$$
\mathrm{L}_{\mathrm{i}}^{\prime}=\mathrm{L}_{\mathrm{i}}+\mathrm{b}_{\mathrm{i}}\left(\mathrm{L}_{\mathrm{NIR}}-\mathrm{Min}_{\mathrm{NIR}}\right) \text {, }
$$

PeerJ reviewing PDF | (2021:06:62143:2:0:NEW 1 Oct 2021) 
195

196

197

198

199

200

201

202

203

204

205

206

207

208

where, L' $i$ is the de-glinted pixel of visible band $i$; $L_{i}$ is reflectance from visible band $i$; $b_{i}$ is the regression slope; $\mathrm{L}_{\mathrm{NIR}}$ is reflectance from NIR band; and $\mathrm{Min}_{\mathrm{NIR}}$ is minimum value of NIR band.

In addition to the sun glint phenomenon, we needed to correct for the water column so that bottom classes were not misclassified due to different water column conditions (Zoffoli, Frouin \& Kampel, 2014). Among various algorithms, Lyzenga's equation (Lyzenga, 1978, 1981) is widely applied to empirically diminish water column attenuation impacts. This method enhances mapping accuracy in digital classification processes of bottom types, and does not require knowing the local depth across every pixel of the scene (Green et al., 2000; Pahlevan, Valadanzouj \& Alimohamadi, 2006; Pu et al., 2012; Zoffoli, Frouin \& Kampel, 2014). The algorithm uses multispectral image datasets to generate 'depth - invariant' coefficients of bottom types from each pair of spectral bands. The result of the correction creates multiple 'depth - invariant bands, replacing original bands to classify bottom features (Green, Mumby, Edwards, \& Clark, 2000). The depth-independent composition of corrected radiance $\left(\mathrm{DII}_{\mathrm{ij}}\right)$ in bands $\mathrm{i}$ and $\mathrm{j}$ (pseudo-color band) was generated by Equation (2):

$$
\mathrm{DII}_{\mathrm{ij}}=\ln \left(\mathrm{L}_{\mathrm{i}}\right)-\left[\left(\frac{\mathrm{k}_{\mathrm{i}}}{\mathrm{k}_{\mathrm{j}}}\right) \ln \left(\mathrm{L}_{\mathrm{j}}\right)\right],
$$

209

210

211

212

213

214

215

216

217

218

219

220

221

222

223

224

225

226

227

228

229

230

\section{Supervised classification and coral cover mapping}

Different types of supervised classification methods have been used to identify coral reefs with water column corrected images and bottom classes in similar marine regions. The Maximum Likelihood Classifier was used due to its effectiveness and adaptability, compared to other classifiers (Ali, Qazi \& Aslam, 2018; Cabral et al., 2018). In the current study, the Maximum Likelihood Classifier was subsequently applied to each image. This classifier was based on a probability density function and guessed the probability with which a specific pixel belongs to a specific category (Richards, 1999). The standard false colour satellite images were composed before applying the supervised classification approach. The standard implementation of supervised maximum likelihood classification required training samples representing the feature types to be classified (Lillesand, Kiefer \& Chipman, 2015). Taking this a-priori knowledge into account, each pixel was labelled as 1LC, 2LC, 3LC, 4LC, HB, S and D (Table 2). Finally, we used a $3 \times 3$ focal majority filter to minimize the "salt-and-pepper effect" in the coral reef maps (Booth \& Oldfield, 1989). 
231 Finally, to validate the classification results, an error matrix was produced to assess the

232

233

234

235

236

237

238

239

240

241

242

243

244

245

246

247

248

249

250

251

252

253

254

255

256

257

258

259

260

261

262

263

264

265

266

267

268

269

performance. We used independent training sites to assess the accuracy of each classification. The error matrix showed seven classes using four metrics: overall accuracy (OA), producer's accuracy (PA), user's accuracy (UA), and the Cohen Kappa coefficient. The Kappa coefficient was computed using equation (3):

$$
K=\frac{\text { Observed Accuracy - Change Agreement }}{1-\text { Change Agreement }}
$$

The Kappa coefficient measures the agreement between the classification and ground-truth values. A Kappa value of 1 represents perfect agreement, while a value of 0 represents no agreement. We interpreted the Kappa values as per Table 3 following (McHugh, 2012; Nguyen, Luong \& Ho, 2015). All the image processing and post-classification steps, presented in Figure 2, were processed using ArcGIS v. 10.8 software packages (ESRI, USA).

Table 3. Interpretation of Kappa values

Figure 2. Flowchart of coral distribution mapping in the study area

\section{Results}

\section{Descriptive field data analysis}

The correlation coefficients and ratio of attenuation coefficients among visible bands at good water penetration (Figure 3). To perform the water column correction, homogenous sand substrates of varying depths collected from field surveys were applied to calculate the ratio of attenuation coefficients. The very high correlation coefficients of 0.95 above were explored between bands 1 and 2, while the relationship between bands 1 and 3 showed high $R^{2}$ values of 0.85 in both ST and CLC.

Figure 3. Transformed band ratios of Planetscope bands in ST [(a) bands 1 and 2, (b) bands 2 and 3, and (c) bands 1 and 3] and in CLC [(d) bands 1 and 2 (e) bands 2 and 3, and (f) bands 1 and 3]

In addition to the water column correction, the study analyzed the spectral signatures among the bottom types (i.e., coral lives and non-coral classes) based on 04 visible bands after corrected sun glint. Many studies measured the spectral characteristics from in situ data or from remotely sensed data (Green et al., 2000; Hochberg, Andréfouët \& Tyler, 2003; Yamano \& Tamura, 2004; Leiper et al., 2014; Giardino et al., 2019). These studies considered that separating spectral features among coral reef bottom classes is challenging. The classes with good separation are sand dominated vs deep water classes representing light and dark objects, respectively (Green et al., 2000; Hochberg, Andréfouët \& Tyler, 2003). Our analysis shows that good discriminating ability

Peer) reviewing PDF | (2021:06:62143:2:0:NEW 1 Oct 2021) 
270 is also found between the D and S classes, while HB bottom easily overlapped with 1LC and 2LC 271 classes in the blue and green bands in both study areas. For live corals, the spectral characteristics 272 utilized a separation among bands blue, red, and NIR (Figure 4). The reflectance of bottom types 273 among these classes decreased in the blue to red bands while increasing at the NIR band. 274 Therefore, the high separation among bands permits the classification of live coral and bottom 275 types in both areas.

276

277

278

279

280

281

282

283

284

285

286

287

288

289

290

291

292

293

294

295

296

297

298

299

300

301

302

303

304

305

306

307

308

Figure 4. Spectral signatures of (a) six classes at ST and (b) seven classes at CLC

\section{The patterns of coral reefs distribution}

From the analysis of field survey results, the most common coral reef types in the study areas were fringing reefs, reefs directly attached to the shoreline of the peninsula and the islands. This reef type varied in relation to a combination of coastline geomorphology and seabed characteristics, normally ranging between 30 and $300 \mathrm{~m}$ in width. The vertical pattern of coral distribution in the study area reached to $14 \mathrm{~m}$ in depth and was densest between 2 and $6 \mathrm{~m}$ (Figure 5).

Figure 5. Depth histogram of coral distribution in (a) Son Tra Peninsula and (b) Cu Lao Cham Island.

The depth distribution of coral reefs and other substrates is presented in Figures 6 and 7 for ST and CLC, respectively. Coral reefs in ST were located along the shoreline from Tien Sa in the northwest to Hon Sup in the southwest. The northwestern most coral reefs in this region were not included in this study due to the high turbidity of the Han estuary. High coral cover was found in the inner coral reefs of the northern ST, while coral cover was patchier in the southern region as shown by the alternating distribution of three classes (1LC, 2LC and 3LC; poor, fair, and good coral cover respectively) across the reef (Figure 6). In southwest ST including Bai Nom, Bai But, and Hon Sup (Figure 6d-e), the reef width ranged between $140-300 \mathrm{~m}$, while across the rest of ST reefs were narrower $(30-90 \mathrm{~m}$ wide).

Figure 6. Coral cover in Son Tra Peninsula (i.e., 1LC: Poor; 2LC: Fair; 3LC: Good; S: Sand; and HB: Hard bottom).

In CLC, coral reefs were located throughout the western and northern shores of Hon Lao (main island) and around small islands (i.e., Hon Kho, Hon La, Hon Mo, Hon Tai, and Hon Dai) (Figure $7 \mathrm{a}, \mathrm{b}, \mathrm{g}$, and $\mathrm{h}$ ). High coral cover was found predominantly in the southern part of the smaller islands, while the northern shores of the islands recorded lower coral cover (Figure 7). The widest reef $(150 \mathrm{~m})$ was the SunGroup reef (near the tourist area managed by SunGroup) while the reef width at the rest of the island locations ranged between 50-100 $\mathrm{m}$. 
309 Figure 7. Coral cover in $\mathrm{Cu}$ Lao Cham Island (i.e., 1LC: Poor; 2LC: Fair; 3LC: Good; 4LC:

310 Excellent; S: Sand; and HB: Hard bottom).

311

312 Following the classification of the bottom cover into different categories (Table 2), we estimated that the live coral areas were $0.47 \mathrm{~km}^{2}$ and $0.58 \mathrm{~km}^{2}$ in the ST and CLC, respectively. Bottom cover proportion is reported in Table 4. In ST, the health condition of ranged from 'poor' to 'fair condition' with $60.25 \%$ classified as a coral reef in poor condition (1LC), $31.88 \%$ in 'fair condition' (2LC), and only 7.87\% in 'good condition' (3LC). Several regions (e.g., Vung Da Ban and Tay Bai Bac - Dong Bai Bac) recorded over $70 \%$ of coral cover in poor condition, while none of the reefs were in good condition or above.

Compared to ST, the health condition of coral reefs in CLC was better and more consistent across reefs. Despite the better condition, the percentage of reefs in poor health still accounted for $34.28 \%$, followed by $2 \mathrm{LC}$ and $3 \mathrm{LC}$ at $28.51 \%$ and $25.75 \%$, respectively. However, the proportion of coral reefs in 'excellent condition' in the CLC was $11.46 \%$, compared to none in the ST. This is perhaps due to several programs to protect and recover coral reefs in the CLC (Hua et al., 2015; Quach, 2018) such as the reef recovery program at some regions of $\mathrm{Cu}$ Lao Cham Island (e.g., Hon Tai, Hon La and Hon Dai, Bai Bac and Bai Huong), which have contributed to coral reef health (Hua et al., 2015).

Table 4. Percentage of coral cover classes in the coral reefs of Son Tra Peninsula and $\mathrm{Cu}$ Lao Cham Island

\section{Performance assessment}

The Planetscope images provided three visible spectral bands that enabled us to penetrate to the water bottom and perform the classification of the benthos (Green et al., 2000; Mumby et al., 2004) and a NIR band that we used for sun-glint removal, subsequently improving the classification accuracy (Hedley, Harborne \& Mumby, 2005; Anggoro, Siregar \& Agus, 2016). Assessments of accuracy were carried out on the coral cover and bottom classes by comparison with geo-rectified ground reference data collected during field surveys. Error matrices were generated for each of the classified images in ST and CLC (Tables 5 and 6, respectively). The overall classification accuracies (Kappa coefficients) for ST and CLC were 78.08\% (0.78) and 76.78\% (0.76), respectively. Among the various coral and bottom types, deep zone and sands class showed the highest producer's accuracies (PA) and user's accuracy (UA) in both regions because of both the exponential decrease of light intensity with increasing depth and the high light absorption through the column before reaching to the deep bottom (Green et al., 2000; Goodman, Purkis \& Phinn, 2013). In the coral cover classification, the highest PA (78.57\%) and UA (80.85\%) were found for 2LC and 3LC, respectively in ST, followed by the $1 \mathrm{LC}$ at $76.56 \%$ and $71.01 \%$, respectively. Whereas these indicators were quite different in CLC. Major areas of confusion and 
348

349

350

351

352

353

354

355

356

357

358

359

360

361

362

363

364

365

366

367

368

369

370

371

372

373

374

375

376

377

378

379

380

381

382

383

384

385

386

387

misinterpretation were found to roughly coincide with the transitional areas between hard bottom (HB) and coral classes.

Table 5. Confusion matrix of bottom types in Son Tra Peninsula

Table 6. Confusion matrix of bottom types in $\mathrm{Cu}$ Lao Cham Island

\section{Discussion}

Coral reef health in almost regions of Viet Nam is declining due to land use conversion at coastal and marine areas under the pressure of economic development (Nguyen \& Nguyen, 2014; Nguyen et al., 2019). Monitoring and detecting coral reefs plays a crucial role in proposing natural resource management policy, environmental management, and conservation efforts (Asner, Martin \& Mascaro, 2017). Using remote sensing tools can address the coral reef health knowledge gap for much of the region. However, the performance remotely sensed image classification depends on the relationship between the spatial resolution of remotely sensed data and the number of categories in the classification (Mumby \& Edwards, 2002; Capolsini et al., 2003; Wicaksono \& Lazuardi, 2018; Li et al., 2019). For example, Wicaksono \& Lazuardi, (2018) presented a range of Kappa values of $0.21-0.40$ by using Planetscope $(3 \mathrm{~m})$ for mapping benthic habitat and seagrass species in Karimunjawa Islands with five classes, while a higher Kappa value of 0.81 was found in Li et al., (2019) by using Dove $(3 \mathrm{~m})$ satellite data to map coral reef habitats in marine the sanctuary Arrecifes del Sureste. Therefore, the selection of adaptive data for coral observation at the region scale was highlighted in this study. The visualization of PlanetScope data for mapping the spatial distribution of benthic community has also been confirmed by recent studies in Viet Nam (Nguyen et al., 2019, b). The first study in Viet Nam using Planetscope images to monitor submerged aquatic vegetation (5 classes) showed a high overall accuracy and Kappa coefficient at $92.52 \%$ and 0.90 , respectively (Nguyen et al., 2019). Therefore, with 07 classification categories, the Kappa coefficients and the overall accuracy in our study indicate sufficient accuracy for post classification assessment.

In addition to Planetscope images, previous studies applied other sensors to explore coral distribution in Viet Nam. For example, Tran, Phinn \& Roelfsema, (2012) used images of IKONOS (3.2 m), QuickBird (2.4 m), and GeoEye-1 (5 m) for categorizing benthic cover. More recently, Nguyen, Luong \& Ho, (2015 and Nguyen, Bui \& Nguyen, (2019) applied medium resolution satellite images [e.g., Landsat 8 OLI (30m), SPOT-5 (10m)] for coral mapping in Ly Son island and Nam Yet island, respectively. However, these studies were only characterized coral cover to other benthic cover and bottom types and unclassified or divided coral lives into separate class. Hence, findings in this study are one of the very first studies applying the Planetscope imagery for monitoring coral cover patterns with 04 coral live classes in the South-Central Coast of Viet Nam. Besides, the outcomes in our study were comparable to those of Capolsini et al., (2003) and Phinn, 
388

389

390

391

392

393

394

395

396

397

398

399

400

401

402

403

404

405

406

407

408

409

410

411

412

413

414

415

416

417

418

419

420

421

422

423

424

425

426

Roelfsema \& Mumby, (2012) that used commercial Quickbird-2 (2.4 m), WorldView-2 (0.5 m), and IKONOS $(3.2 \mathrm{~m})$ images, respectively to explore coral reefs. Here we affirm the potential of Planetscope imagery for visualizing higher resolution coral health monitoring metrics. This approach is expected to provide managers with more accurate data, reduce time, manpower and cost in marine conservation in developing countries.

We mapped coral distribution in ST and CLC as a case study of the South-Central Coast region in Viet Nam. However, some limitations have been discovered. Offsets associated with the difference between the actual positions and field locations when a scuba diver took underwater photos and GPS estimates from the surface reduced spatial certainty to 5 X 5. Hence, around deep-water areas (15 $\mathrm{m}$ depth) especially where the bottom morphology is narrow, each photograph covered an area over $5 \mathrm{~m}^{2}$, reducing the number of field images for bottom feature identification. Besides, around the field sites with homogenous bottom characteristics (i.e., sand, hard bottom, and deep water), individual photos and the camera of 360 CND713 were used to record the bottom, to identify neighboring areas, and to enhance the ground truth data for the D class. Therefore, the number of filtered and random ground truth data to perform error matrix for post classification in this study reduced.

For future research, a time-series of PlanetScope images should be obtained and applied to explore the spatiotemporal pattern of coral reef variation. Besides, intersection between coral pattern and various information layers (e.g., geology, climatic condition, biomes, land use and land cover change) should be employed to better understand distribution and diversity and to propose strategies for coral conversation. Nonetheless, optimizing the data collection and analysis related to classification and field survey methods should be compared to enhance accuracy assessment.

\section{Conclusions}

The distribution of coral reefs (coral cover and bottom types) in ST and CLC in the South-Central Coast of Viet Nam was characterized using very high spatial resolution (3 m) Planetscope imagery with a supervised classification approach. Seven classes, including coral reef health (04 classes) and bottom types ( 03 classes), were categorized to determine coral cover and condition of the reefs in the study area. Field surveys of 1,543 photographs in ST and 1,560 photographs in CLC were used to assess accuracy.

The study characterized coral reefs distribution and health in a peninsula setting and offshore islands. The results revealed that the overall condition of coral reef was of 'poor condition' in the Son Tra (60.25\%) and ranged between 'fair and good condition' in CLC. Additionally, the reefs in both areas were predominantly fringing reef, reaching a depth of $14 \mathrm{~m}$ and a width of $400 \mathrm{~m}$. In ST, there were better environmental conditions in the southern area than in the northern area which was indicated by the higher density of live coral in Hon Sup, Mui Nghe and Mui Gion. In CLC, 
427 there was higher coral cover in the south such as in Bai Nan, Bai Huong, Hon Dai and SunGroup

428 than in the north and center of both small and large islands, and Hon Tai in the south.

429

430 Accuracy assessment of the classified images using Maximum Likelihood classifier showed 431 satisfactory performance and a high accuracy in both areas with an overall accuracy of $75 \%$ and 432 Kappa coefficients of $>0.75$. Therefore, the overall approach provides an accessible means for reef 433 scientists and managers to effectively apply remotely sensed data to observe coral ecosystems. The 434 findings of this study can provide a comprehensive understanding of coral pattern and support 435 policymakers/planners to develop appropriate coral reefs conservation policies in coastal regions.

436

437 Acknowledgements

438 The authors would like to thank the Planet Education and Research Program for supporting the

439 Planetscope images in this research.

440

441

References

442

443

444

Ali MZ, Qazi W, Aslam N. 2018. A comparative study of ALOS-2 PALSAR and landsat-8 imagery for land cover classification using maximum likelihood classifier. The Egyptian Journal of Remote Sensing and Space Science 21:S29-S35. DOI: $10.1016 / j . e j r s .2018 .03 .003$.

Asner GP, Martin RE, Mascaro J. 2017. Coral reef atoll assessment in the South China Sea using Planet Dove satellites. Remote Sensing in Ecology and Conservation 3:57-65. DOI: $10.1002 /$ rse 2.42

Booth DJ, Oldfield RB. 1989. A comparison of classification algorithms in terms of speed and accuracy after the application of a post-classification modal filter. International Journal of Remote Sensing 10:1271-1276. DOI: 10.1080/01431168908903965 
457

458

459

460

461

462

463

464

465

466

467

468

469

470

471

472

473

474

475

476

477

478

479

Maximum Likelihood and Classification and Regression Trees. ISPRS Journal of Photogrammetry and Remote Sensing 142:94-105. DOI: 10.1016/j.isprsjprs.2018.05.007.

Capolsini P, Andréfouët S, Rion C, Payri C. 2003. A comparison of Landsat ETM+, SPOT HRV, Ikonos, ASTER, and airborne MASTER data for coral reef habitat mapping in South Pacific islands. Canadian Journal of Remote Sensing 29:187-200. DOI: 10.5589/m02-088

Carriger JF, Yee SH, Fisher WS. 2021. Assessing coral reef condition indicators for local and global stressors using Bayesian networks. Integrated Environmental Assessment and Management 17:165-187. DOI: 10.1002/ieam.4368

Chou L, Wilkinson CC, Licuanan W, Alino PP, Cheshire AA, Loo M, Tangjaitrong SS, Sudara SS, Ridzwan A, Soekarno SS. 1995. Status of coral reefs in the ASEAN region. In: Proceedings, Third ASEAN-Australia Symposium on Living Coastal Resources, Chulalongkorn University, Bangkok, Thailand, 16-20 May 1994. Volume 1. Status Reviews-pages: 1-10. Australian Institute of Marine Science (AIMS).

Gabr B, Ahmed M, Marmoush Y. 2020. PlanetScope and landsat 8 imageries for bathymetry mapping. Journal of Marine Science and Engineering 8:143.DOI: 10.3390/jmse8020143

Giardino C, Brando VE, Gege P, Pinnel N, Hochberg E, Knaeps E, Reusen I, Doerffer R, Bresciani M, Braga F. 2019. Imaging spectrometry of inland and coastal waters: state of the art, achievements and perspectives. Surveys in Geophysics 40:401-429. DOI: 10.1007/s10712018-9476-0

Gonzalez-Rivero M, Beijbom O, Rodriguez-Ramirez A, Bryant DE, Ganase A, Gonzalez-Marrero Y, Herrera-Reveles A, Kennedy EV, Kim CJ, Lopez-Marcano S. 2020. Monitoring of coral reefs using artificial intelligence: A feasible and cost-effective approach. Remote Sensing 12:489. DOI: $10.3390 /$ rs 12030489 
480 Goodman J, Purkis S, Phinn S. 2013. Coral Reef Remote Sensing: A Guide for Mapping, 481 Monitoring and Management. Springer Netherlands. DOI: 10.1007/978-90-481-9292-2.

482 Green E, Mumby P, Edwards A, Clark C. 2000. Remote sensing: handbook for tropical coastal 483 management. Paris, France: United Nations Educational, Scientific and Cultural $484 \quad$ Organization (UNESCO).

485 Guan Y, Hohn S, Wild C, Merico A. 2020. Vulnerability of global coral reef habitat suitability to 486 ocean warming, acidification and eutrophication. Global Change Biology 26:5646-5660. DOI: $10.1111 / \mathrm{gcb} .15293$

488

489

490

491

492

493

494 495

496

497

498

499

500

501

502

Hedberg N, Stenson I, Kautsky N, Hellström M, Tedengren M. 2017. Causes and consequences of spatial links between sea cage aquaculture and coral reefs in Vietnam. Aquaculture 481:245-254. DOI: 10.1016/j.aquaculture.2017.09.009.

Hedley JD, Harborne AR, Mumby PJ. 2005. Simple and robust removal of sun glint for mapping shallow-water benthos. International Journal of Remote Sensing 26:2107-2112. DOI: $10.1080 / 01431160500034086$

Hedley JD, Roelfsema C, Brando V, Giardino C, Kutser T, Phinn S, Mumby PJ, Barrilero O, Laporte J, Koetz B. 2018. Coral reef applications of Sentinel-2: Coverage, characteristics, bathymetry and benthic mapping with comparison to Landsat 8. Remote sensing of environment 216:598-614. DOI: 10.1016/j.rse.2018.07.014

Hedley JD, Roelfsema CM, Chollett I, Harborne AR, Heron SF, Weeks S, Skirving WJ, Strong AE, Eakin CM, Christensen TR. 2016. Remote sensing of coral reefs for monitoring and management: a review. Remote Sensing 8:118. DOI: 10.3390/rs8020118

Hill J, Wilkinson C. 2004. Methods for ecological monitoring of coral reefs. Australian Institute of Marine Science, Townsville 117. 
503 Hoang MD, Tran VB, Le D, To VQ, Hoang QH. 2019. Distribution of terrestrial fauna on Son Tra 504 Peninsula, Da Nang City. The University of Danang, Journal of Science and Technology 505 17:34-39. DOI: 10.31130/jst-ud2019-116e.

506 Hochberg EJ, Andréfouët S, Tyler MR. 2003. Sea surface correction of high spatial resolution 507 508 Ikonos images to improve bottom mapping in near-shore environments. IEEE transactions on geoscience and remote sensing 41:1724-1729. DOI: 10.1109/TGRS.2003.815408

509

510

511

512

513

514

515

516

517

518

519

520

521

522

523

524

Hoegh-Guldberg O, Pendleton L, Kaup A. 2019. People and the changing nature of coral reefs. Regional Studies in Marine Science 30:100699. DOI: 10.1016/j.rsma.2019.100699

Hua TT, Vo ST, Phan KH, Huynh ND. 2015. Survival and growth rate of hard corals rehabilitated in $\mathrm{Cu}$ Lao Cham marine protected area, Quang Nam province. Collection of Marine Research Works 21:94-102.

Kay S, Hedley JD, Lavender S. 2009. Sun Glint Correction of High and Low Spatial Resolution Images of Aquatic Scenes: a Review of Methods for Visible and Near-Infrared Wavelengths. Remote Sensing 1:697-730. DOI: 10.3390/rs1040697.

Kimura T, Tun K, Chou L. 2014. Status of Coral Reefs in East Asian Seas Region: 2014. Tokyo, Japan: Ministry of the Environment of Japan and Japan Wildlife Research Center.

Kimura T, Tun K, Chou L. 2018. Status of Coral Reefs in East Asian Seas Region: 2018. Tokyo, Japan: Ministry of the Environment of Japan and Japan Wildlife Research Center.

Kohler KE, Gill SM. 2006. Coral Point Count with Excel extensions (CPCe): A Visual Basic program for the determination of coral and substrate coverage using random point count methodology. Computers \& geosciences 32:1259-1269. DOI:10.1016/j.cageo.2005.11.009 
525 Latypov YuYa, Selin NI. 2008. Coral communities of barrier reefs of Vietnam. Russian Journal 526 of Marine Biology 34:143-150. DOI: 10.1134/S1063074008030012.

527 Lazuardi W, Wicaksono P, Marfai MA. 2021. Remote sensing for coral reef and seagrass cover

528

529

530

531

532

533

534

535

536

537

538

539

540

541

542

543

544

545

546 mapping to support coastal management of small islands. In: IOP Conference Series: Earth and Environmental Science. IOP Publishing, 012031. DOI: 10.1088/17551315/686/1/012031

Le DD. 2020. The status of coral reefs in central Vietnam's coastal water under climate change. Aquatic Ecosystem Health \& Management 23:323-331. DOI: $10.1080 / 14634988.2020 .1819715$

Leiper IA, Phinn SR, Roelfsema CM, Joyce KE, Dekker AG. 2014. Mapping coral reef benthos, substrates, and bathymetry, using compact airborne spectrographic imager (CASI) data. Remote Sensing 6:6423-6445. DOI: 10.3390/rs6076423

Lemajic S, Vajsová B, Aastrand P. 2018. New Sensors Benchmark Report on PlanetScope: Geometric Benchmarking Test for Common Agricultural Policy (CAP) Purposes. European Commission: Brussels, Belgium. DOI: 10.2760/178918

Levy J, Hunter C, Lukacazyk T, Franklin EC. 2018. Assessing the spatial distribution of coral bleaching using small unmanned aerial systems. Coral Reefs 37:373-387. DOI: $10.1007 / \mathrm{s} 00338-018-1662-5$

Li J, Schill SR, Knapp DE, Asner GP. 2019. Object-based mapping of coral reef habitats using planet dove satellites. Remote Sensing 11:1445. DOI: 10.3390/rs11121445

Lillesand T, Kiefer RW, Chipman J. 2015. Remote sensing and image interpretation. John Wiley \& Sons, Hoboken, NJ 07030-5774. 
547 Lyzenga DR. 1978. Passive remote sensing techniques for mapping water depth and bottom

548

549

550

551

552

553

554

555

556

557

558

559

560

561

562

563

564

565

566

567

568 features. Applied optics 17:379-383.DOI: 10.1364/AO.17.000379

Lyzenga DR. 1981. Remote sensing of bottom reflectance and water attenuation parameters in shallow water using aircraft and Landsat data. International journal of remote sensing 2:71-82. DOI: 10.1080/01431168108948342

Mansaray AS, Dzialowski AR, Martin ME, Wagner KL, Gholizadeh H, Stoodley SH. 2021. Comparing PlanetScope to Landsat-8 and Sentinel-2 for Sensing Water Quality in Reservoirs in Agricultural Watersheds. Remote Sensing 13:1847. DOI: $10.3390 /$ rs 13091847

McCarthy MJ, Colna KE, El-Mezayen MM, Laureano-Rosario AE, Méndez-Lázaro P, Otis DB, Toro-Farmer G, Vega-Rodriguez M, Muller-Karger FE. 2017. Satellite remote sensing for coastal management: A review of successful applications. Environmental management 60:323-339. DOI: $10.1007 / \mathrm{s} 00267-017-0880-\mathrm{x}$

McHugh ML. 2012. Interrater reliability: the kappa statistic. Biochemia Medica 22:276-282.

Mumby PJ, Edwards AJ. 2002. Mapping marine environments with IKONOS imagery: enhanced spatial resolution can deliver greater thematic accuracy. Remote sensing of environment 82:248-257. DOI: 10.1016/S0034-4257(02)00041-X

Mumby PJ, Skirving W, Strong AE, Hardy JT, LeDrew EF, Hochberg EJ, Stumpf RP, David LT. 2004. Remote sensing of coral reefs and their physical environment. Marine pollution bulletin 48:219-228. DOI: 10.1016/j.marpolbul.2003.10.031

Nguyen VL. 2009. Coral reef fishes in the coastal waters of south-central Vietnam. Vietnam Journal of Marine Science and Technology 9. DOI: 10.15625/1859-3097/9/3/6273

Peer) reviewing PDF | (2021:06:62143:2:0:NEW 1 Oct 2021) 
569 Nguyen XT, Bui TBA, Nguyen TN. 2019. Research on marine environment and coral distribution 570 on Nam Yet island using VNRedsat-1 and QuickBird images. Vietnam Journal of Marine 571 Science and Technology 19:189-202. DOI: 10.15625/1859-3097/19/3B/14525

572 Nguyen XT, Dang TBA, Nguyen TN, Pham DH. 2019a. Study on spatial distribution of coral reefs 573 in Nam Yet island by using GIS and remote sensing techniques. Vietnam Journal of Marine Science and Technology 19:177-187. DOI: 10.15625/1859-3097/19/3B/14524

575 Nguyen T, Huynh T, Zhang H. 2015. Cu Lao Cham biosphere reserve sustainability project In 576 Vietnam: corporate framework for sustainable development management. Sustainable Development (2 Volume Set) 168:115. DOI: 10.2495/SD150021

578 579 580

Nguyen HQ, Luong VT, Ho DD. 2015. Study on spatial distribution of coral reefs in Ly Son Island using GIS and remote sensing technique. Vietnam Journal of Marine Science and Technology 15:264-272. DOI: 10.15625/1859-3097/15/3/7222

Nguyen QC, Nguyen VC. 2014. Integrated coastal management in Vietnam: current situation and orientation. Vietnam Journal of Marine Science and Technology 14:89-96. DOI:10.15625/1859-3097/14/1/4034

Nguyen TTH, Nguyen TH, Nguyen VT, Nguyen NL. 2019a. Spatial distribution of submerged aquatic vegetation in An Chan coastal waters, Phu Yen province using the PlanetScope satellite image. Vietnam Journal of Earth Sciences 41:358-373. DOI: 10.15625/0866$7187 / 41 / 4 / 14237$

Nguyen TTH, Nguyen TH, Tong PHS, Nguyen NL. 2019b. Vegetation Biomass of Sargassum Meadows in An Chan Coastal Waters, Phu Yen Province, Vietnam Derived from PlanetScope Image. Journal of Environmental Science and Engineering 8:81-92. DOI: $: 10.17265 / 2162-5263 / 2019.03 .001$ 
592 Nguyen VL, Phan HK. 2008. Distribution and factors influencing on structure of reef fish 593 communities in Nha Trang Bay Marine Protected Area, South-Central Vietnam. 594 Environmental biology of fishes 82:309-324. DOI: 10.1007/s10641-007-9293-7

595 Nguyen VL, Vo ST. 2013. Degradation trend of coral reefs in the coastal waters of Vietnam. 596 Galaxea, Journal of Coral Reef Studies 15:79-83. DOI: 10.3755/galaxea.15.79.

597 Obura DO, Aeby G, Amornthammarong N, Appeltans W, Bax N, Bishop J, Brainard RE, Chan S, 598 Fletcher P, Gordon TA. 2019. Coral reef monitoring, reef assessment technologies, and

599

600 ecosystem-based management. Frontiers in Marine Science 6:580. DOI:

601 602 603 604 605 606 607 608 609 610 10.3389/fmars.2019.00580

Pahlevan N, Valadanzouj MJ, Alimohamadi A. 2006. A quantitative comparison to water column correction techniques for benthic mapping using high spatial resolution data. In: Proceedings of the ISPRS Commission VII Mid-term Symposium-Remote Sensing, from Pixels to Processesll, Enschede, The Netherlands. Citeseer, 8-11.

Pawlik JR, McMurray SE. 2020. The emerging ecological and biogeochemical importance of sponges on coral reefs. Annual review of marine science 12:315-337. DOI: 10.1146/annurev-marine-010419-010807

Phinn SR, Roelfsema CM, Mumby PJ. 2012. Multi-scale, object-based image analysis for mapping geomorphic and ecological zones on coral reefs. International Journal of Remote Sensing 33:3768-3797. DOI: 10.1080/01431161.2011.633122

Pu R, Bell S, Meyer C, Baggett L, Zhao Y. 2012. Mapping and assessing seagrass along the western coast of Florida using Landsat TM and EO-1 ALI/Hyperion imagery. Estuarine, Coastal and Shelf Science 115:234-245. DOI: 10.1016/j.ecss.2012.09.006 
614 Quach TKN. 2018. Impacts on the ecosystem and human well-being of the marine protected area 615 in $\mathrm{Cu}$ Lao Cham, Vietnam. Marine Policy 90:174-183. DOI:

616 617 618

619

620

621

622

623

624

625

626

627

628

629

630

631

632

633

634

635

636 10.1016/j.marpol.2017.12.015.

Richards JA. 1999. Remote sensing digital image analysis. Berlin, Germany: Springer.

Roelfsema CM, Phinn SR, Joyce KE. 2006. Evaluating benthic survey techniques for validating maps of coral reefs derived from remotely sensed images. In: Proc 10th Int Coral Reef Symp. Citeseer, 1771-1780.

Tobler, W.R. (1988) Resolution, resampling and all that. In Mounsey, H. and Tomlinson, R., Editors, Building Databases for Global Science. London: Taylor and Francis, p.129-137.

Tran VD, Phinn S, Roelfsema C. 2012. Coral Reef Mapping in Vietnam's Coastal Waters from High-spatial Resolution Satellite and Field Survey Data. Asian Journal of Geoinformatics 12.

Tun K, Chou LM, Yeemin T, Phongsuwan N, Amri AY, Ho N, Sour K, Long N, Nanola C, Lane D. 2008. Status of coral reefs in Southeast Asia. In: Status of coral reefs of the world. Townsville: Australian Institute of Marine Science, 131-144.

Wang M, Bailey SW. 2001. Correction of sun glint contamination on the SeaWiFS ocean and atmosphere products. Applied Optics 40:4790-4798. DOI: 10.1364/AO.40.004790

Wicaksono P, Lazuardi W. 2018. Assessment of PlanetScope images for benthic habitat and seagrass species mapping in a complex optically shallow water environment. International journal of remote sensing 39:5739-5765. DOI: 10.1080/01431161.2018.1506951

Wulandari SA, Wicaksono P. 2021. Bathymetry mapping using PlanetScope imagery on Kemujan Island, Karimunjawa, Indonesia. In: IOP Conference Series: Earth and Environmental Science. IOP Publishing, 012032. 
637 Yamano H, Tamura M. 2004. Detection limits of coral reef bleaching by satellite remote sensing: 638 simulation and data analysis. Remote sensing of environment 90:86-103. DOI: $639 \quad 10.1016 / j . r s e .2003 .12 .005$

640 Zhou Z, Ma L, Fu T, Zhang G, Yao M, Li M. 2018. Change Detection in Coral Reef Environment 641 Using High-Resolution Images: Comparison of Object-Based and Pixel-Based Paradigms. 642 ISPRS International Journal of Geo-Information 7:441. DOI: 10.3390/ijgi7110441.

643 Zoffoli ML, Frouin R, Kampel M. 2014. Water Column Correction for Coral Reef Studies by $644 \quad$ Remote Sensing. Sensors 14:16881-16931. DOI: 10.3390/s140916881.

645

646 
Figure 1

Location of study area (a) Son Tra Peninsula (ST) and (b) Cu Lao Cham Island (CLC).

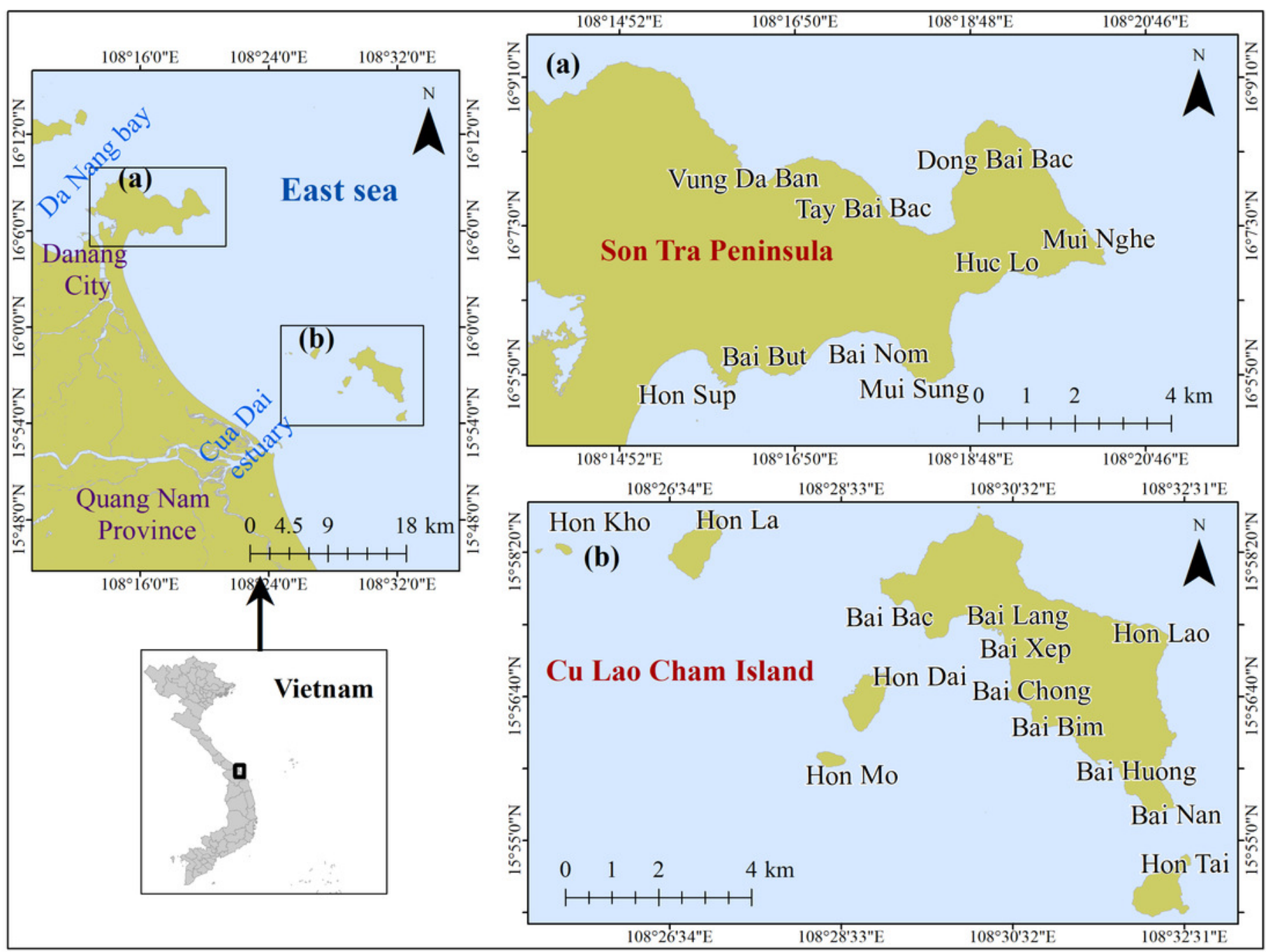


Figure 2

Flowchart of coral distribution mapping in the study area. 


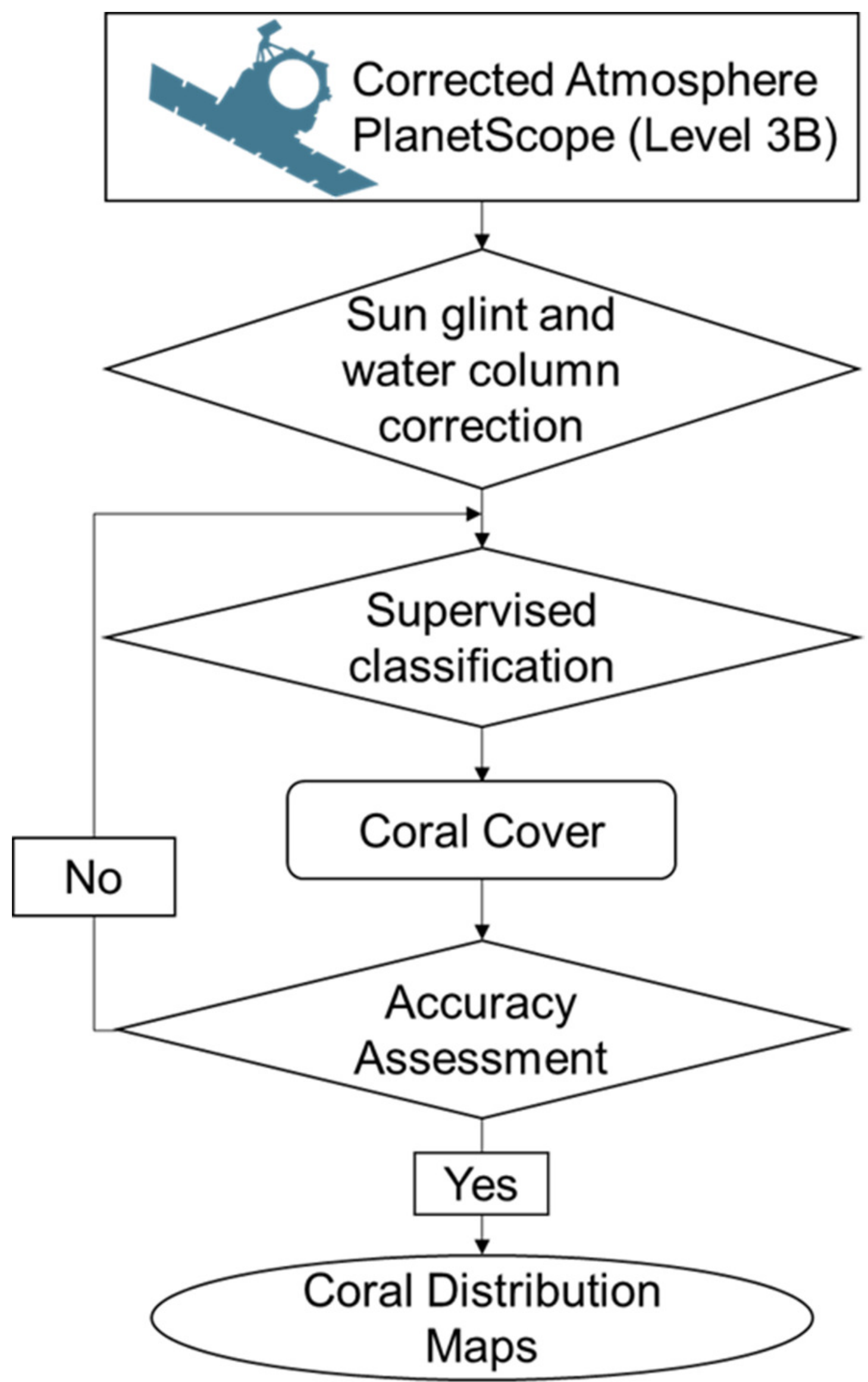


Figure 3

Transformed band ratios of Planetscope bands in ST [(a) bands 1 and 2, (b) bands 2 and 3, and (c) bands 1 and 3] and in CLC [(d) bands 1 and 2 (e) bands 2 and 3, and (f) bands 1 and 3].
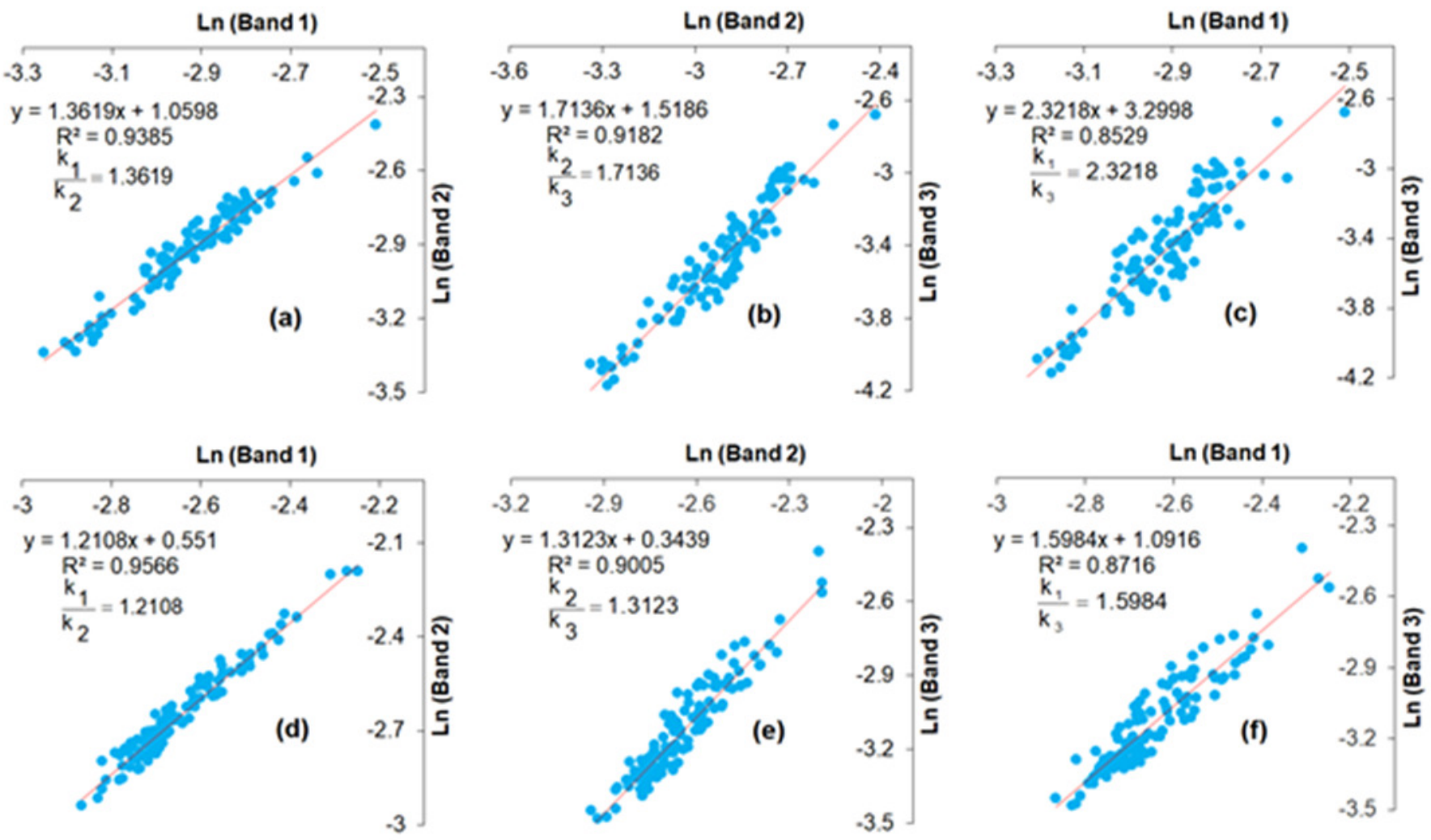
Figure 4

Spectral signatures of (a) six classes at ST and (b) seven classes at CLC.

0.054

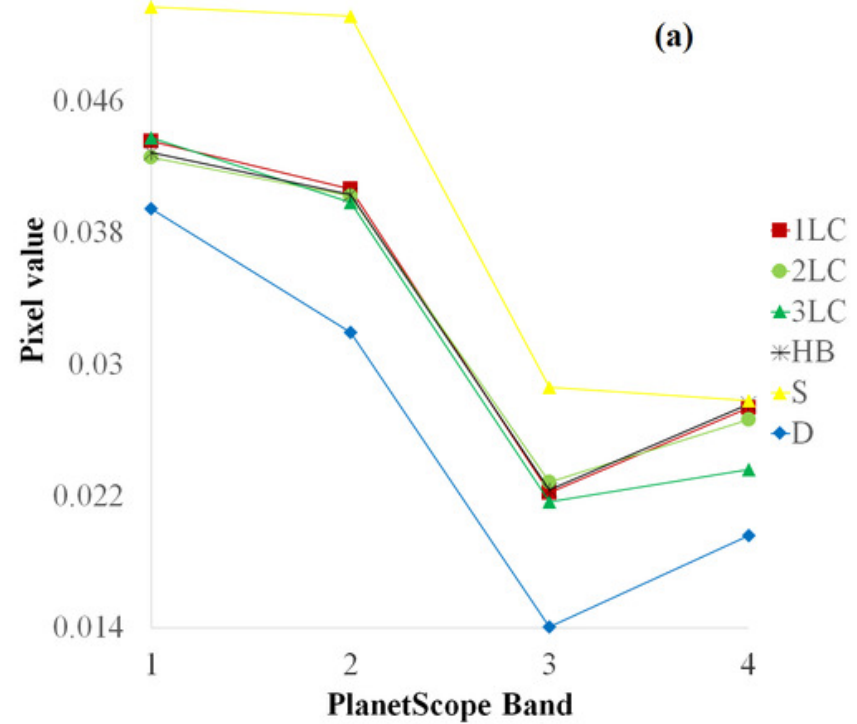

0.07

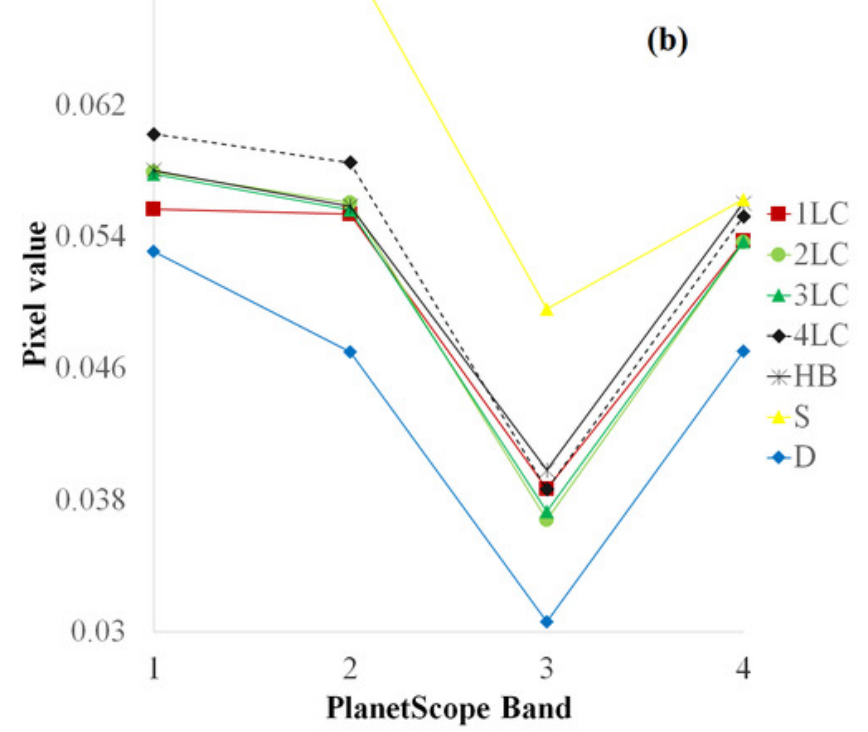


Figure 5

Depth histogram of coral distribution in (a) Son Tra Peninsula and (b) Cu Lao Cham Island.
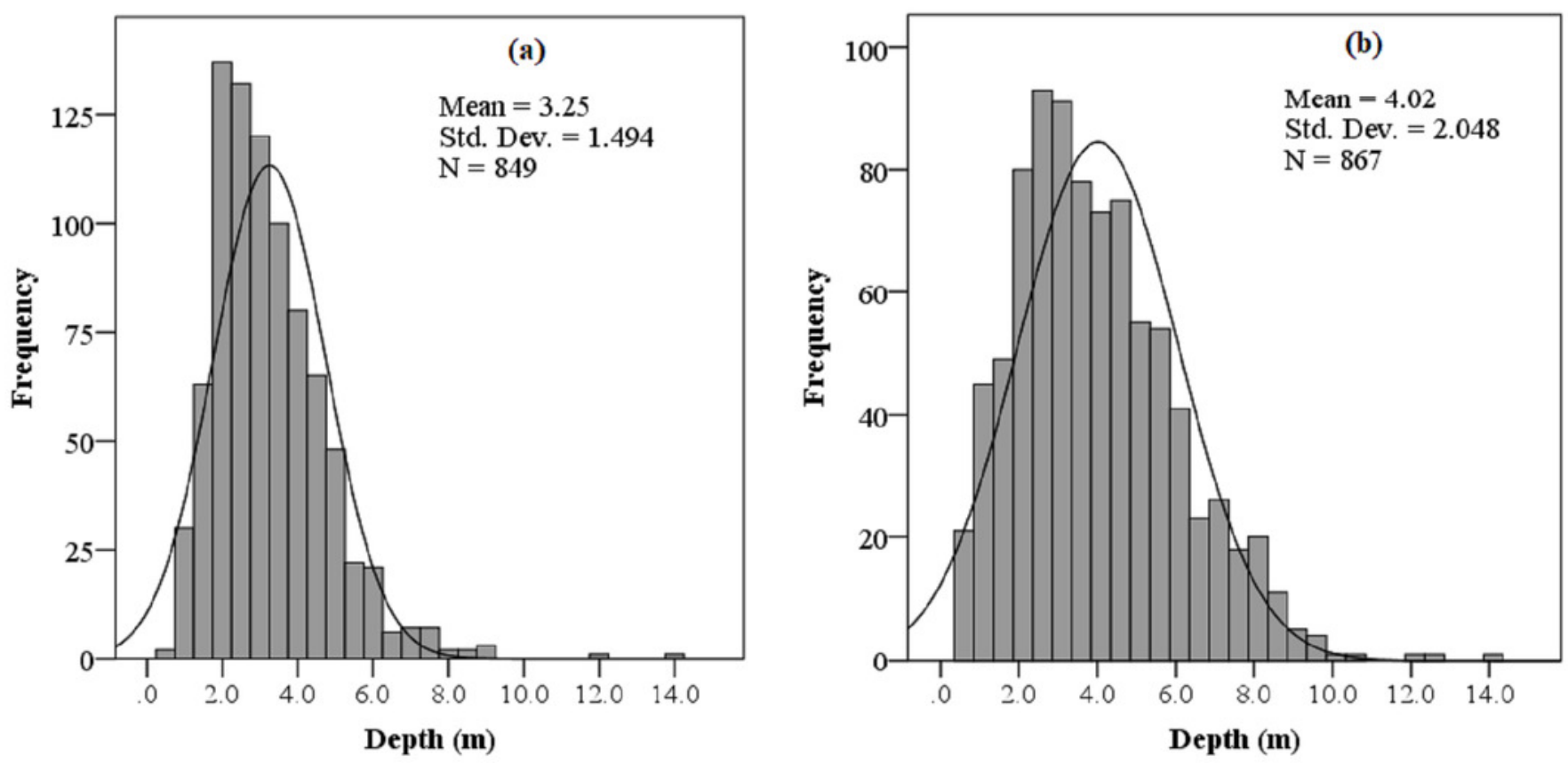
Figure 6

Coral cover in Son Tra Peninsula.

1LC: Poor; 2LC: Fair; 3LC: Good; S: Sand; and HB: Hard bottom
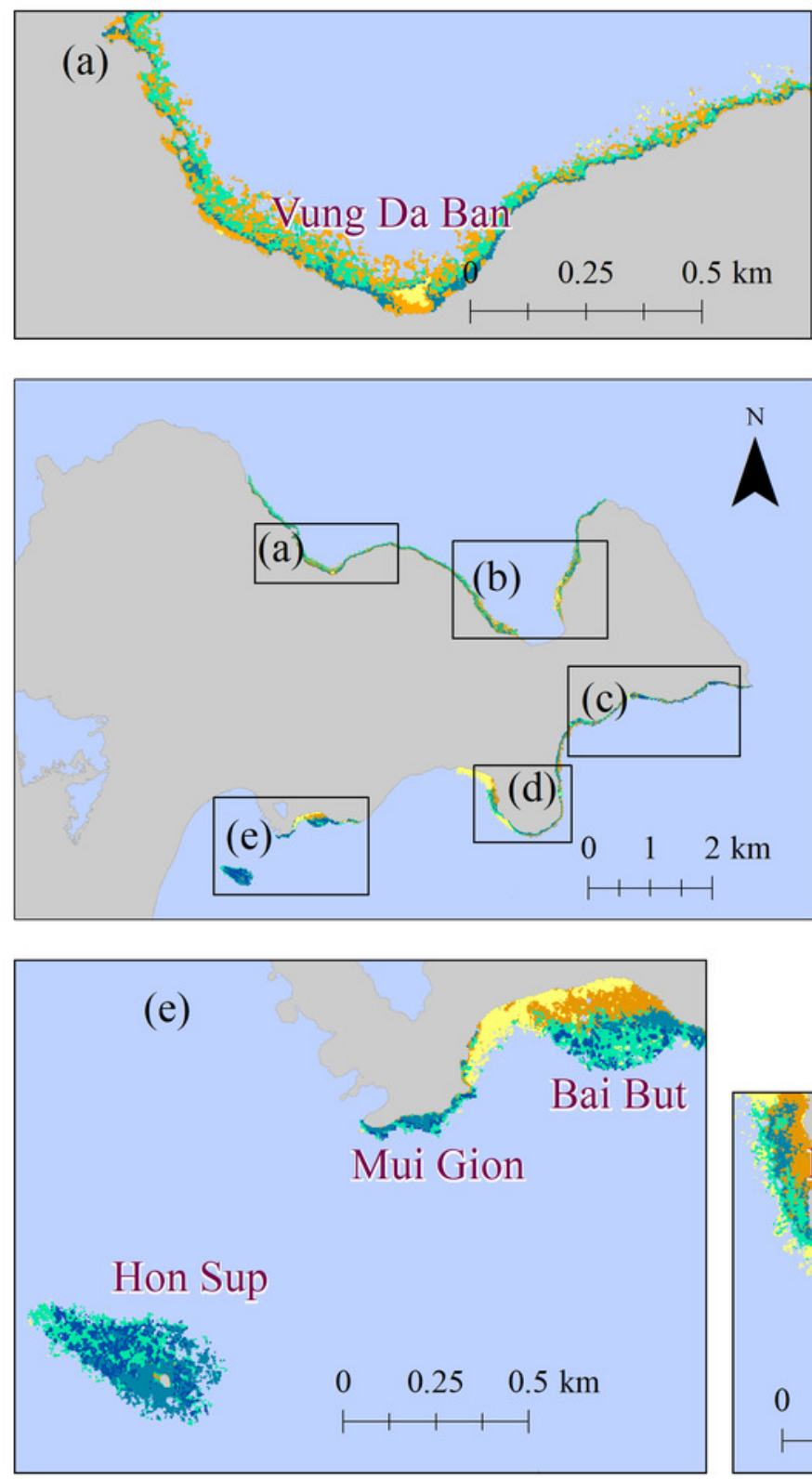
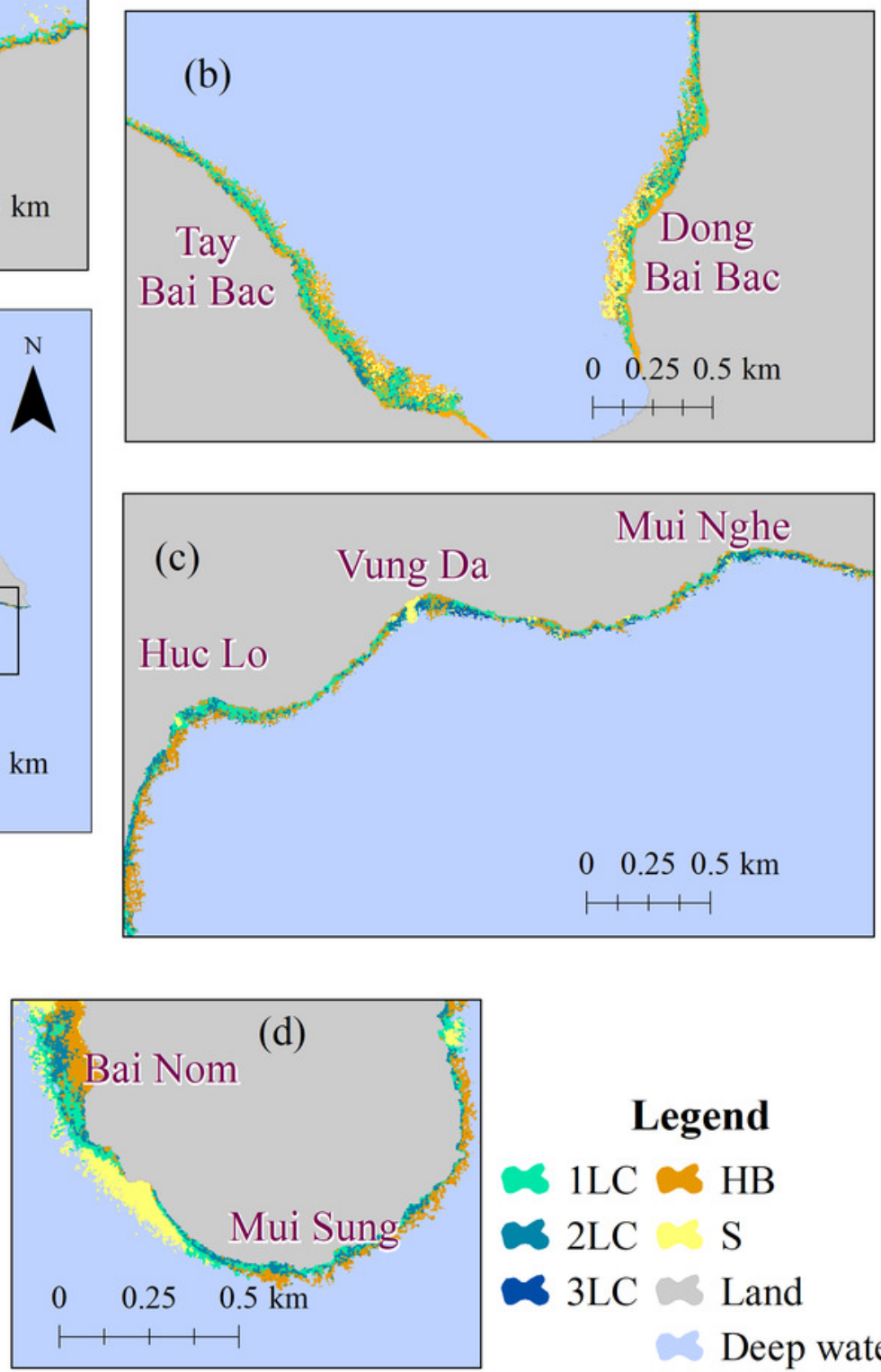

Legend

$\because$ 1LC $\sim \mathrm{HB}$

$\sim 2 \mathrm{LC} \quad \mathrm{S}$

$\checkmark$ 3LC $\rightarrow$ Land

Deep water 
Figure 7

Coral cover in Cu Lao Cham Island.

1LC: Poor; 2LC: Fair; 3LC: Good; 4LC: Excellent; S: Sand; and HB: Hard bottom
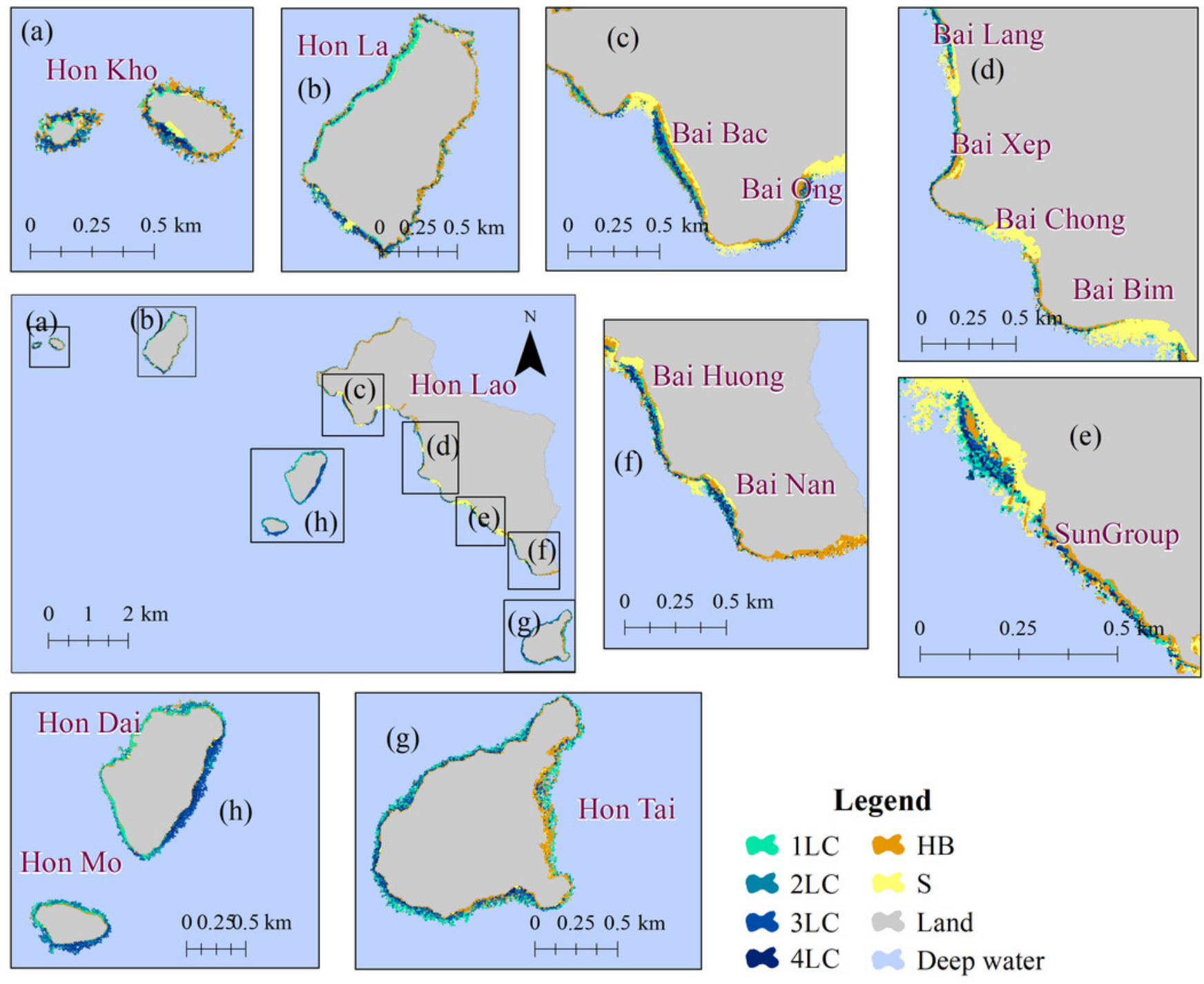
Table $\mathbf{1}$ (on next page)

Details of the acquired Planetscope imagery. 


\begin{tabular}{ccccc}
\hline Location & Row & Path & Data of Acquisition & Spatial resolution \\
\hline Son Tra & 021 & 858 & 28 June 2019 & \\
& & 859 & & \\
$\mathrm{Cu}$ Lao Cham & 025 & 351 & 08 August 2019 \\
\hline
\end{tabular}

1 
Table 2 (on next page)

Identification scheme of bottom types and coral reef health. 


\begin{tabular}{|c|c|c|c|c|c|c|}
\hline Class & Detail & $\begin{array}{c}\text { Class } \\
\text { description }\end{array}$ & $\begin{array}{c}\text { Coral reef } \\
\text { health } \\
\text { criteria } \\
\end{array}$ & Label & $\begin{array}{c}\text { Depth } \\
\text { range (m) }\end{array}$ & Sample image \\
\hline \multirow{4}{*}{$\begin{array}{l}\text { Live } \\
\text { coral } \\
(\mathrm{LC})\end{array}$} & \multirow{4}{*}{$\begin{array}{l}\text { hard and } \\
\text { soft coral }\end{array}$} & $0<\mathrm{LC} \leq 25 \%$ & Poor & $1 \mathrm{LC}$ & $\begin{array}{c}\text { ST: } 0.8-8.5 \\
\text { CLC: } 0.6- \\
11.5\end{array}$ & \\
\hline & & $25<\mathrm{LC} \leq 50 \%$ & Fair & $2 \mathrm{LC}$ & $\begin{array}{c}\text { ST: } 0.5-8.2 \\
\text { CLC: } 0.9- \\
9.9\end{array}$ & \\
\hline & & $50<\mathrm{LC} \leq 75 \%$ & Good & $3 \mathrm{LC}$ & $\begin{array}{c}\text { ST: } 1.3-7 \\
\text { CLC: } 0.8- \\
\quad 10.2\end{array}$ & \\
\hline & & $\mathrm{LC}>75 \%$ & Excellent & $4 \mathrm{LC}$ & $\begin{array}{c}\text { CLC: } 0.9- \\
10.5\end{array}$ & \\
\hline $\begin{array}{l}\text { Sand } \\
(\mathrm{S})\end{array}$ & $\begin{array}{c}\text { Sand } \\
\text { dominated }\end{array}$ & $\begin{array}{c}\mathrm{LC}=0 \% \text { and } \\
\mathrm{S} \geq 50 \% \mathrm{~S}\end{array}$ & & $\mathrm{~S}$ & $\begin{array}{c}\text { ST: } 0.5- \\
13.1 \\
\text { CLC: } 0.4- \\
12.5\end{array}$ & \\
\hline $\begin{array}{c}\text { Hard } \\
\text { bottom }\end{array}$ & $\begin{array}{l}\text { Rock, } \\
\text { rubble, } \\
\text { dead } \\
\text { structure }\end{array}$ & $\begin{array}{c}\mathrm{LC}=0 \% \mathrm{LC} \\
\text { and } \mathrm{HB}>50 \%\end{array}$ & & HB & $\begin{array}{c}\mathrm{ST}: 1-8.2 \\
\mathrm{CLC}: 0.7- \\
10.5\end{array}$ & \\
\hline $\begin{array}{l}\text { Deep } \\
\text { zone }\end{array}$ & & Depth $>14 \mathrm{~m}$ & & $\mathrm{D}$ & $\begin{array}{c}\text { ST: } 14-24 \\
\text { CLC: } 14- \\
29.5\end{array}$ & \\
\hline
\end{tabular}


Table 3 (on next page)

Interpretation of Kappa values. 


\begin{tabular}{ll}
\hline Value & Description \\
\hline Less than 0 & Less than chance agreement \\
\hline $0.01-0.2$ & Sigh agreement \\
\hline $0.21-0.40$ & Fair agreement \\
\hline $0.41-0.60$ & Moderate agreement \\
\hline $0.61-0.80$ & Substantial agreement \\
\hline $0.81-1.00$ & Almost perfect agreement \\
\hline
\end{tabular}

1 


\section{Table 4 (on next page)}

Percentage of coral cover classes in the coral reefs of Son Tra Peninsula and Cu Lao Cham Island. 


\begin{tabular}{|c|c|c|c|c|c|}
\hline Location & Level (\%) & $1 \mathrm{LC}$ & $2 \mathrm{LC}$ & 3LC & $4 \mathrm{LC}$ \\
\hline \multirow{6}{*}{ Son Tra } & Vung Da Ban & 75.19 & 24.81 & - & - \\
\hline & $\begin{array}{l}\text { Tay Bai Bac - Dong Bai } \\
\text { Bac }\end{array}$ & 71.05 & 28.95 & - & - \\
\hline & Mui Nghe - Huc Lo & 48.68 & 38.06 & 13.26 & - \\
\hline & Mui Sung - Bai Nom & 59.48 & 40.52 & - & - \\
\hline & Bai But - Hon Sup & 46.51 & 33.76 & 19.73 & - \\
\hline & Total & 60.25 & 31.88 & 7.87 & - \\
\hline \multirow{9}{*}{$\begin{array}{l}\text { Cu Lao } \\
\text { Cham }\end{array}$} & Hon Kho & 20.15 & 36.26 & 30.42 & 13.17 \\
\hline & Hon La & 42.08 & 28.21 & 22.67 & 7.04 \\
\hline & $\begin{array}{l}\text { North of main island } \\
\text { (NI) to Bai Ong }\end{array}$ & 15.54 & 54.31 & 25.76 & 4.39 \\
\hline & Harbour - Bai Bim & 32.87 & 38.29 & 21.46 & 7.38 \\
\hline & SunGroup & 45.1 & 13.49 & 25.26 & 16.15 \\
\hline & Bai Huong - Bai Nan & 33.54 & 19.15 & 25.98 & 21.33 \\
\hline & Hon Tai & 46.26 & 19.7 & 26.81 & 7.23 \\
\hline & Hon Mo - Hon Dai & 31.59 & 23.78 & 27.07 & 17.56 \\
\hline & Total & 34.28 & 28.51 & 25.75 & 11.46 \\
\hline
\end{tabular}




\section{Table 5 (on next page)}

Confusion matrix of bottom types in Son Tra Peninsula. 


\begin{tabular}{ccccccccc}
\hline Class & 1LC & 2LC & 3LC & HB & S & D & Total & UA \\
\hline 1LC & $\mathbf{4 9}$ & 5 & 3 & 7 & 3 & 2 & 69 & $\mathbf{7 1 . 0 1}$ \\
2LC & 5 & $\mathbf{4 4}$ & 10 & 3 & 1 & 1 & 64 & $\mathbf{6 8 . 7 5}$ \\
3LC & 1 & 7 & $\mathbf{3 8}$ & 1 & 0 & 0 & 47 & $\mathbf{8 0 . 8 5}$ \\
HB & 6 & 0 & 0 & $\mathbf{3 2}$ & 3 & 2 & 43 & $\mathbf{7 4 . 4 2}$ \\
S & 1 & 0 & 0 & 3 & $\mathbf{4 1}$ & 6 & 51 & $\mathbf{8 0 . 3 9}$ \\
D & 2 & 0 & 1 & 1 & 1 & $\mathbf{4 4}$ & 49 & $\mathbf{8 9 . 8}$ \\
\hline Total & 64 & 56 & 52 & 47 & 49 & 55 & OV & $\mathbf{7 6 . 7 8}$ \\
PA & $\mathbf{7 6 . 5 6}$ & $\mathbf{7 8 . 5 7}$ & $\mathbf{7 3 . 0 8}$ & $\mathbf{6 8 . 0 9}$ & $\mathbf{8 3 . 6 7}$ & $\mathbf{8 0}$ & KC & $\mathbf{0 . 7 6}$ \\
\hline
\end{tabular}


Table 6(on next page)

Confusion matrix of bottom types in Cu Lao Cham Island. 


\begin{tabular}{cccccccccc}
\hline Class & 1LC & 2LC & 3LC & 4LC & HB & S & D & Total & UA \\
\hline 1LC & $\mathbf{4 7}$ & 7 & 1 & 3 & 2 & 1 & 1 & 62 & $\mathbf{7 5 . 8 1}$ \\
2LC & 3 & $\mathbf{4 6}$ & 5 & 2 & 0 & 0 & 0 & 56 & $\mathbf{8 2 . 1 4}$ \\
3LC & 0 & 7 & $\mathbf{4 3}$ & 3 & 1 & 0 & 0 & 54 & $\mathbf{7 9 . 6 3}$ \\
4LC & 0 & 4 & 5 & $\mathbf{4 0}$ & 6 & 0 & 0 & 55 & $\mathbf{7 2 . 7 3}$ \\
HB & 5 & 4 & 2 & 0 & $\mathbf{3 0}$ & 1 & 1 & 43 & $\mathbf{6 9 . 7 7}$ \\
S & 0 & 2 & 0 & 0 & 6 & 43 & 4 & 55 & $\mathbf{7 8 . 1 8}$ \\
D & 1 & 2 & 0 & 0 & 2 & 0 & 39 & 44 & $\mathbf{8 8 . 6 4}$ \\
\hline Total & 56 & 72 & 56 & 48 & 47 & 45 & 45 & OV & $\mathbf{7 8 . 0 5}$ \\
PA & $\mathbf{8 4}$ & $\mathbf{6 3 . 8 9}$ & $\mathbf{7 6 . 7 9}$ & $\mathbf{8 3 . 3 3}$ & $\mathbf{6 3 . 8 3}$ & $\mathbf{9 5 . 5 6}$ & $\mathbf{8 6 . 6 7}$ & KC & $\mathbf{0 . 7 8}$ \\
\hline
\end{tabular}

1 